\title{
The traumatized ischiopubic synchondrosis: a rare cause of acute hip pain
}

\author{
Justus H. W. Jansen • Aernout R. J. Langeveld •
}

J. A. Niesten

Received: 31 May 2011 / Accepted: 23 June 2011 / Published online: 12 July 2011

(C) The Author(s) 2011. This article is published with open access at Springerlink.com

\section{Introduction}

Epiphyseal growth plates developing during skeletal maturation are the most common temporary synchondroses in childhood. The fibrocartilaginous bridge between the superomedial pubic and the inferolateral ischial ossification center is defined as the ischiopubic synchondrosis (IPS). It is considered to be a physiologic developmental stage that can be recognized on conventional radiographs as a fusiform radiolucent area at the ischiopubic zone [1, 2]. The ossification of IPS begins early in childhood and is usually completed before puberty. While usually asymptomatic, the ossification process can be accompanied by pain in the groin and restriction in the movement of the hip joint $[3,4]$.

Although stress fractures have been described to mimic the symptomatic IPS ossification, a traumatic fracture of the IPS as a cause of hip pain has not yet specifically been reported.

\section{Case report}

An otherwise healthy 8-year-old girl visited our orthopedic outpatient department in a wheelchair. Almost 2 weeks earlier, she had fallen on her left hip during ice-skating. Although she was able to continue her activity, increasing pain on the lateral side of her left hip had caused her to limp

J. H. W. Jansen $(\varangle) \cdot$ A. R. J. Langeveld $\cdot$ J. A. Niesten Department of Orthopaedics, Reinier de Graaf Gasthuis, Reinier de Graafweg 3-11, Delft, 2625 AD, The Netherlands

e-mail: j.jansen@erasmusmc.nl progressively over the next couple of days. At the time of presentation, she could not bear weight. There was no history of recent illness.

Physical examination of the hips did not reveal signs of hematoma, infection, or other external abnormalities. There was clear tenderness on palpation around the greater trochanteric area on the lateral side of the left hip. Hip movement was slightly diminished and painful on the lateral side of the hip, but not in the groin.

The pelvic AP and Lauenstein radiographs did not show indications of a fracture, epiphysiolysis, or Perthes disease. Bilateral radiolucent fusiform widening of the IPS was considered physiological (Fig. 1). Blood laboratory tests showed no abnormalities, with normal leukocyte count, C-reactive protein levels, and sedimentation rate.

Adaptation of weight bearing was advised. As the pain continued to prevent her from bearing weight over the next couple of weeks, additional pelvic MR imaging was performed. A hypointense linear band was observed in both left and right IPS on $\mathrm{T}_{1}$ and $\mathrm{T}_{2}$. On the left side, a hyperintense signal of the ischiopubic zone and adjacent soft tissue was seen on $\mathrm{T}_{2}$ with fat saturation (Fig. 2). Combined with the clinical presentation, a fracture of the left IPS was diagnosed.

A watchful waiting policy was deployed that resulted in a spontaneous improvement of pain and hip function. Three months after the traumatic event, all symptoms had subsided.

\section{Discussion}

Acute unilateral hip pain during childhood can be a diagnostic challenge [5, 6]. Septic arthritis and epiphysiol- 

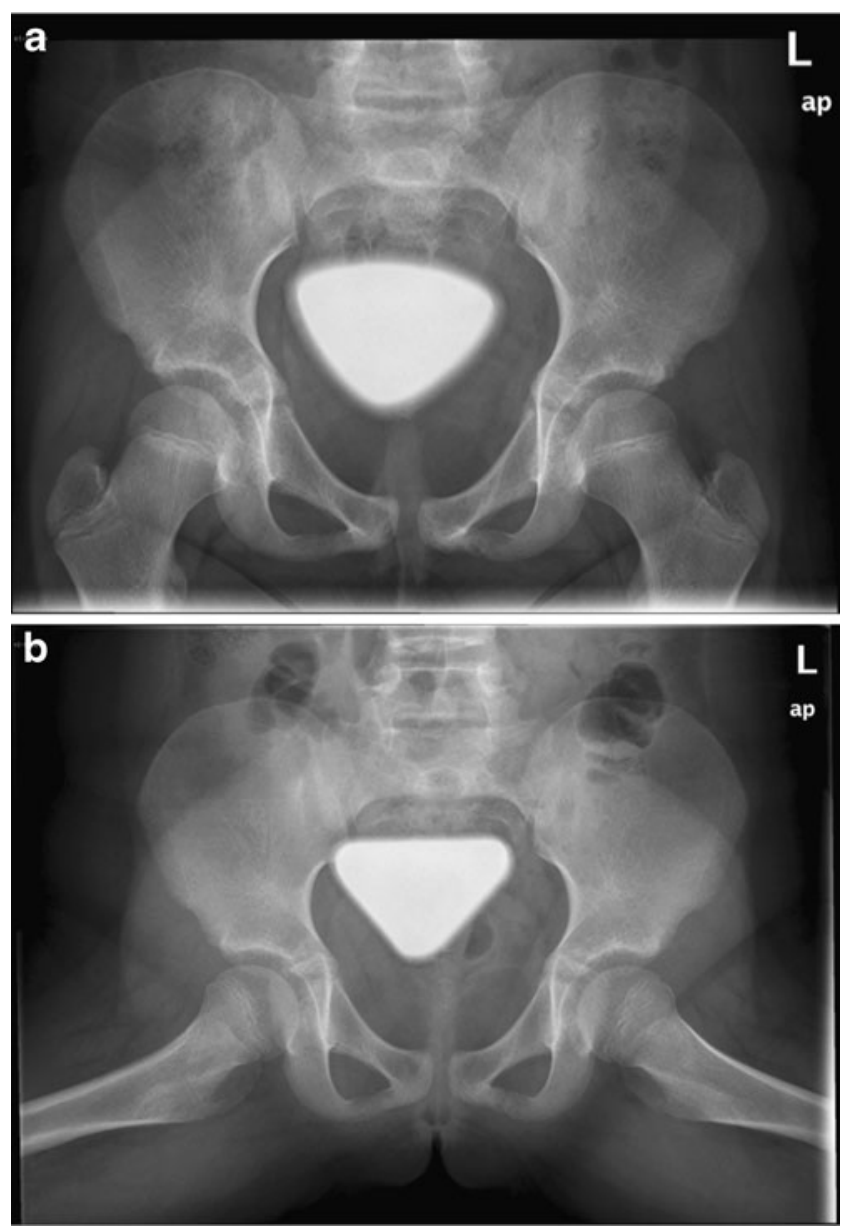

Fig. 1 Conventional pelvic AP (a) and Lauenstein (b) radiographs showing bilateral radiolucent fusiform enlargement at the ischiopubic zone, consistent with IPS

ysis require prompt treatment and should be ruled out. In addition, non-specific clinical presentation in children may warrant a clear diagnosis. While traumatic lesions of the IPS are uncommon and usually not visible using plain radiographs, they can easily be missed.

Additional pelvic MR imaging is helpful to diagnose such a lesion, although interpretation can be challenging. Signal alterations of the ischiopubic fusion zone in the asymptomatic IPS are frequently observed. Herneth et al. retrospectively screened for IPS on pelvic MR imaging performed in children [7]. They found IPS with signal alteration of the ischiopubic fusion zone to occur in $61 \%$ of their population. Typically, a hyperintense signal on $T_{2}$ with fat saturation or STIR, and a hypointense signal on $\mathrm{T}_{1}$ is noted. Additionally, fibrous bridging and fusiform swelling can be observed, accompanied by signal alteration of the adjacent soft tissue. Although usually presenting bilaterally, IPS signal alterations on MR imaging were found to occur unilaterally in one third of the population.
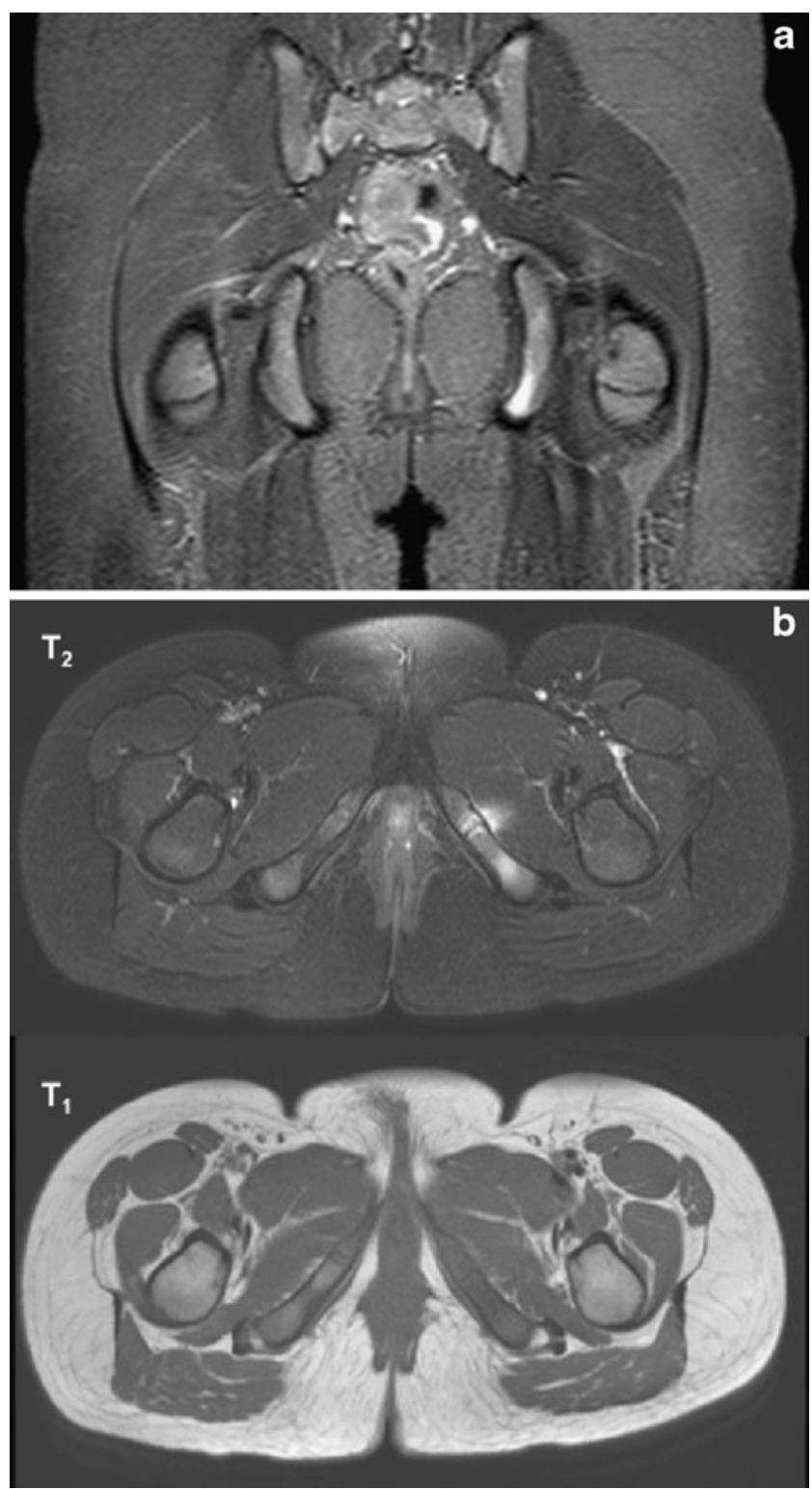

Fig. 2 Pelvic MR imaging in coronal (a) and transversal (b) planes. A hypointense linear band was observed in both left and right IPS on $T_{1}$ and $\mathrm{T}_{2}$. On the left side, a hyperintense signal of the ischiopubic zone and adjacent soft tissue was seen on $\mathrm{T}_{2}$ with fat saturation

A fracture of the IPS can feature similar signal alterations, but is importantly characterized by a hypointense linear band. It is distinguishable from fibrous bridging mainly via clinical presentation [7].

MR imaging performed in children with persisting posttraumatic pain is a valuable tool to diagnose a synchondrosis lesion and exclude other pathology.

Conflict of interest The authors declare that they have no conflict of interest. 
Open Access This article is distributed under the terms of the Creative Commons Attribution Noncommercial License which permits any noncommercial use, distribution, and reproduction in any medium, provided the original author(s) and source are credited.

\section{References}

1. Van Neck M (1924) Osteochondrite du pubis. Arch Franco-Bel Chir 27:238-341

2. Keats $T$ (1996) Atlas of normal roentgen variants that may simulate disease. In., 6th edn. Mosby-Year Book, St. Louis, pp $316-318$
3. Nowakowski A, Napiontek M (1990) Aseptic necrosis of ischiopubic synchondrosis (osteochondrosis ischiopubica) as the cause of diagnostic difficulties in pathology if the infantile hip. Chir Narzadow Ruchu Ortop Pol 55(1):43-45

4. Neitzschman HR (1997) Radiology case of the month. Hip trauma. Normal physiologic asymmetric closure of the ischiopubic synchondroses. J La State Med Soc 149(6):186-188

5. Oliveira F (2010) Differential diagnosis in painful ischiopubic synchondrosis (IPS): a case report. Iowa Orthop J 30:195-200

6. Perry DC, Bruce C (2010) Evaluating the child who presents with an acute limp. BMJ 341:c4250

7. Herneth AM, Trattnig S, Bader TR, Ba-Ssalamah A, Ponhold W, Wandl-Vergesslich K, Steinbach LS (2000) MR imaging of the ischiopubic synchondrosis. Magn Reson Imaging 18(5):519-524 